DR. ROMINA CLARA SCARDAMAGLIA (Orcid ID : 0000-0002-5400-6083)

DR. JUAN CARLOS REBOREDA (Orcid ID : 0000-0001-5136-4574)

Article type : Original Paper

Editor: Sumasgutner, Petra

Running-head: Roosting behaviour in brood parasitic cowbirds

\title{
Roosting behaviour is related to reproductive strategy in brood parasitic cowbirds
}

ROMINA C. SCARDAMAGLIA, ${ }^{1 *}$ ALEX KACELNIK ${ }^{2}$ \& JUAN C. REBOREDA ${ }^{1}$

${ }^{1}$ Departamento de Ecología, Genética y Evolución \& IEGEBA-CONICET, Facultad de

Ciencias Exactas y Naturales, Universidad de Buenos Aires, Pabellón II Ciudad

Universitaria, C1428EGA Buenos Aires, Argentina

${ }^{2}$ Department of Zoology, South Parks Road, University of Oxford, OX1 3PS, United Kingdom

${ }^{\star}$ Corresponding author: rscardamaglia @ ege.fcen.uba.ar.

Shiny Cowbirds Molothrus bonariensis and Screaming Cowbirds M. rufoaxillaris are closely related brood parasites, but the former is socially polygynous or promiscuous and an extreme host generalist, while the latter is socially monogamous and parasitizes almost exclusively one host. Females of both species lay in relative darkness, before dawn, relying This article has been accepted for publication and undergone full peer review but has not been through the copyediting, typesetting, pagination and proofreading process, which may lead to differences between this version and the Version of Record. Please cite this article as doi: 10.1111/ibi. 12587

This article is protected by copyright. All rights reserved. 
for host nest location on previous days' prospecting activity, or possibly on following betterinformed roost associates. We studied the temporal and spatial patterns of roosting behaviour in these species to test the hypothesis that roosting behaviour of cowbirds is related to their breeding strategy (brood parasitism) and reflects differences in strategies between species. We recorded fidelity to a roost, location fidelity within a roost, interindividual spatial associations, and timing of roost departures and parasitic events, using tagged individuals. Female Shiny Cowbirds and both sexes of Screaming Cowbirds showed marked fidelity in roosting location, and roost departures occurred both during and after the known time window for parasitism, with earlier departures probably corresponding to laying days. Screaming Cowbird females and males that were trapped together and showed high levels of association during the day also showed high levels of association in the roost. We describe the spatial and temporal patterns of a relatively poorly known aspect of avian ecology in general and of brood parasites' behaviour in particular.

Keywords: bird assemblage, space use, site fidelity, radio-tracking, Molothrus.

It is common in many bird species for individuals to gather in groups ranging from a few to many thousands to spend the overnight resting period together (Dhondt et al. 2006, Winkler 2006, Laughlin et al. 2014). Though a widespread behaviour, the functional significance of communal roosting remains poorly understood, and may have different explanations across taxa. Functions proposed for roosts include thermoregulation, reduction in probability of predation, and information exchange, and some studies have provided direct or indirect evidence for each of these factors in specific systems (see Yom-Tov 1979, du Plessis et al. 1994, Paquet et al. 2016). An influential hypothesis elaborated by Ward and Zahavi (1973) proposed that bird assemblages such as roosts could act as information centres, where individuals that do not have information on the location of good feeding sites can obtain such

This article is protected by copyright. All rights reserved. 
knowledge from individuals that do, but the empirical evidence is inconclusive and unlikely to apply equally across communally roosting species (Weatherhead 1987).

Only a few studies have analysed the activity of birds in roosts, and among those most have focused mainly on two aspects: roost site fidelity (Morrison \& Caccamise 1985, Conklin et al. 2007, Béchet et al. 2010, Laughlin et al. 2014) and roost-use in relation to feeding sites (Morrison \& Caccamise 1985, 1990, Conklin et al. 2007, Adams 2011). These studies have shown great variability in roost site fidelity both between and within species. In Common Starlings Sturnus vulgaris, for example, some individuals remain highly faithful to a roost, whereas others frequently switch between different roosts in the area (Morrison \& Caccamise 1985). Tree Swallows Tachycineta bicolor return to the roost previously used about $60 \%$ of the time, and when they do switch roosts, roost significantly closer to their original roosting site than would be expected if they were choosing randomly among the roosts in the area (Laughlin et al. 2014). However, Dunlin Calidris alpina use roosts that are closer to their last foraging locations than roosts that are also known to them and in which they have roosted before (Adams 2011). In addition, and contradicting expectations from the 'information centre' hypothesis for roost function (Ward \& Zahavi 1973), Common Starlings were found to be more faithful to their diurnal feeding ranges than to their communal roosting sites, with birds commuting from up to five different communal roosts to a stable diurnal range (Morrison \& Caccamise 1985).

Brood parasites, such as cuckoos and cowbirds, exploit the parental care of other species (hosts) by laying their eggs in their nests. The use of roosts in relation to brood parasites' reproductive strategy has not yet been studied, except for a few secondary or anecdotal mentions in studies analysing home-ranges and activity patterns in the Brownheaded Cowbird Molothrus ater (Thompson 1994, Gates \& Evans 1998, Hahn et al. 1999) and one study that addressed roost departure times in Shiny Cowbirds M. bonariensis (Feare \& Zaccagnini 1993).

This article is protected by copyright. All rights reserved. 
Females of the host generalist Shiny Cowbird and the host specialist Screaming Cowbird M. rufoaxillaris lay their eggs around dawn (Gloag et al. 2013, Scardamaglia et al. 2017) in nests that they visited on previous days (Scardamaglia et al. 2017). It is known that cowbirds roost communally (Cruz et al. 1990, Feare \& Zaccagnini 1993), and evidence suggests that they fly directly from their roost to target nests (Scardamaglia \& Reboreda 2014). In addition to differences in the degree of specialization in host use, Shiny and Screaming Cowbirds differ in their mating systems: Shiny Cowbirds are socially polygynous or promiscuous and females search for nests without the assistance of the male, while Screaming Cowbirds are socially monogamous and males accompany females when they search for nests (Mason 1987, Scardamaglia \& Reboreda 2014). Social behaviour varies throughout the day: during the morning individuals are found alone or in small groups, while in the afternoon they gather to feed in larger flocks (Scardamaglia \& Reboreda 2014, Kattan et al. 2016), grouping in communal roosts towards sunset. A similar behaviour has been observed in the Brown-headed Cowbirds Molothrus ater, a closely related species, in which males and females spend the morning in small groups in areas rich in host nests, joining large feeding flocks in the afternoon and roosting communally at night (Thompson 1994, Gates \& Evans 1998).

In this study we test the hypothesis that roosting behaviour in cowbirds is related to their breeding strategy (brood parasitism) and reflects differences in strategies between species. The differences between the mating systems of Shiny and Screaming Cowbirds led us to expect differences in roosting behaviour between the males of the two species, but not between the females. We studied roosting site use at two different scales: first, we studied fidelity between roosts (i.e. whether individuals joined one or more roost communities), and second, their location fidelity within roost (i.e. whether individuals settled randomly within their roost each night or showed preference for particular locations). Because female Shiny Cowbirds search for nests in daytime and must reach the same nests in the following morning twilight, they face the navigational problem of reaching a different nest location

This article is protected by copyright. All rights reserved. 
every laying day in the dark. One might expect this to affect their choice of roosting site, but how is not obvious. Since roosting may be constrained to dark, dense forest sites for predation reasons, Shiny Cowbirds may benefit from roosting at consistent locations in order to start laying expeditions in well-known areas. Host nests are typically in relatively open sites, where twilight navigation may be easier. On the other hand, if navigation towards host nests were not a problem, they could reduce the distance travelled for each laying trip by changing roosting site between nights. The same reasoning can be applied to both sexes of Screaming Cowbirds, which jointly visit host nests, but not to male Shiny Cowbirds, that do not participate in nest scouting or dawn-laying trips. Given their spatial association during the day and joint nest-searching, we expected Screaming Cowbird pairs to roost in close proximity. Furthermore, because laying occurs mostly during the dawn twilight, when poor light intensity is unsuited to searching for nests or foraging, early roost departures may only occur on the fraction of days on which females are ready to lay.

\section{METHODS}

\section{Study site and species}

The study was conducted at the reserve 'El Destino' (35.141오, 57.393W), near the town of Magdalena, in Buenos Aires Province, Argentina, during the breeding seasons (OctoberFebruary) $2010 / 11$ to $2013 / 14$. The area comprises $\sim 500$ ha of flooding grasslands with interspersed woodland patches dominated by two low, spiny trees, spiny hackberry Celtis ehrenbergiana and coronillo Scutia buxifolia. Screaming and Shiny Cowbirds are year-round residents in the area. At this field site Shiny Cowbirds intensely parasitize the Chalk-browed Mockingbird Mimus saturninus (frequency of parasitism 70-80\%, Fiorini \& Reboreda 2006; Gloag et al. 2012) and to a lesser degree other species such as the House Wren Troglodytes aedon (frequency of parasitism: 50\%, Tuero et al. 2007). Chalk-browed Mockingbirds breed from mid-September until mid-January and build open-cup nests in

This article is protected by copyright. All rights reserved. 
shrubs or trees with dense foliage, at a height of $1.5-2.5 \mathrm{~m}$. They lay $3-5$ eggs per clutch, and if a nest fails, the same pair can attempt re-nesting several times (Fraga 1985). Screaming Cowbirds parasitize exclusively the Greyish Baywing Agelaioides badius. The frequency of parasitism is $80-90 \%$ and most nests are parasitized multiple times (Fraga 1998, Mason 1980, De Mársico et al. 2010). Greyish Baywings rarely build their own nest. Instead, they breed in domed nests built by other species, secondary cavities, or nest boxes (Friedmann 1929, Hoy \& Ottow 1964, Fraga 1998, De Mársico et al. 2010). They breed from early December to late February and are cooperative breeders. Assisted pairs generally have one to three helpers, which are recruited after egg hatching (Fraga 1991, Ursino et al. 2011).

\section{Radio-telemetry}

We trapped 36 Shiny Cowbirds (27 females and 9 males) and 32 Screaming Cowbirds (27 females and 5 males) during the breeding seasons (October-February) 2010/11 to 2013/14 using walk-in funnel traps baited with millet, or mist-nets. The difference between the sexes in the number of birds trapped and tagged was due to the fact that in a concurrent project (Scardamaglia et al. 2017) we were more interested in female behaviour, resulting in a greater number of tagged females. Each bird was marked with a unique combination of colour plastic leg bands and a numbered aluminium band and was fitted with a radio-tag. Two Shiny Cowbird females were tagged twice, in 2010/11 and 2013/14, and one female in three breeding seasons, in 2010/11, 2011/12 and 2013/14. We used two different types of radio-tags because this study was carried out simultaneously with two other projects (Scardamaglia \& Reboreda 2014, Scardamaglia et al. 2017). During the breeding seasons 2010/11 and 2011/12 the animals were fitted with $1.2 \mathrm{~g}$ glue-on beeper-VHF radiotransmitters (model PicoPip Ag392 from Biotrack, Wareham, UK or model A2455 from Advanced Telemetry Systems, Isanti, Minnesota, USA). We glued the radio-transmitters to

This article is protected by copyright. All rights reserved. 
the bird's back using cyanoacrylate adhesive and an activator (Loctite 401 and Loctite 770, Henkel, respectively). During the $2012 / 13$ and $2013 / 14$ breeding seasons the animals were fitted with $1.0 \mathrm{~g}$ backpack coded radio-tags (model NTQB-4-2, Lotek Wireless, Ontario, Canada) using Teflon Ribbon (Bally Ribbon Mills, Philadelphia, USA) and the Rappole harness technique (Rappole \& Tipton 1991). The procedure of marking the cowbird and fitting the radio-transmitter lasted less than 15 minutes. These two different techniques yielded differences in the time the birds carried the transmitters. Birds fitted with glue-on radio-tags carried them for $35.8 \pm 21.0$ days (mean \pm sd, range $=6$ - 68 days, $n=34$, see Scardamaglia \& Reboreda 2014), while those fitted with backpack tags carried them for the whole duration of tag life (tags were designed to run for 79 days). We found that the variables we measured (see below) did not differ significantly between tagging methods (see Online Supporting Material for more details). The radio-tags had no obvious effects on cowbirds' behaviour, since females visited and parasitized nests as soon as $18 \mathrm{~h}$ after tag deployment (see SM1 in Scardamaglia et al. 2017).

To determine roost locations, we tracked cowbirds on foot, using the homing technique (White \& Garrott 1990). Cowbirds were monitored around dusk using hand-held radio-tracking receivers (beeper tags: model Sika, Biotrack, Wareham, UK; coded tags: model SRX-400A, Lotek Wireless, Ontario, Canada). The coded tags hand-held receiver range was limited: it required for the distance between receiver and tag to be no more than $20 \mathrm{~m}$ for proper code reading. Because some of the Screaming Cowbirds roosted in a deep forest area where access was difficult in the dark and impeded reliable identification of the birds, we present fewer data for this species. We recorded departure times from roosts using a hand-held receiver each morning from $04: 30 \mathrm{~h}$ to $06: 30 \mathrm{~h}$ in 47,34 and 29 days in the breeding seasons 2010/11, 2011/12 and 2013/14 respectively. A departure was detected when the tag signal was recorded moving away (and eventually lost) from the fixed location the bird had maintained in the roost the previous night. During the day, we tracked cowbirds

This article is protected by copyright. All rights reserved. 
on foot to check that the radio-tags were still active and that the birds remained in the area (and that any absence from the roost was not due to a faulty or lost radio-tag).

To detect parasitic events from tagged females, in all seasons we video-recorded activity in mockingbird nests using a camera (Handykam 420 CCD colour micro-camera) suspended above the nest and connected to a digital video recorder (Lawmate PVR1000 or PVR500 ECO) placed at the base of the tree. We did not video record baywing nests since they are prone to desert if disturbed during the pre-laying or laying period (M. C. De Mársico pers. comm.). Additionally, during the seasons 2012/13 and 2013/14, we recorded tagged Shiny and Screaming Cowbird visits to host nests using digitally encoded proximity dataloggers (DataSika, Biotrack, Wareham, UK) that were connected to an omnidirectional antenna (Biotrack, Wareham, UK) and to a $12 \mathrm{~V}$ car battery. The data-loggers continually 'listened' for nearby tags and recorded the tag identity code, date and time whenever a tagged cowbird came within detection range, $\sim 30 \mathrm{~m}$ from the antenna (see Scardamaglia et al. 2017 for more details on recording of visits of tagged birds to host nests). We placed the data loggers on the ground directly below 29 mockingbird and 16 baywing nests (Fig. 1) that were in the construction or pre-laying stages (defined as the time lapsed since nest lining is completed and the host lays its first egg). We monitored nest activity continuously, from the moment that the data logger was deployed until 3-4 days after the onset of incubation or nest failure (i.e. abandonment or depredation), whichever occurred first. Overall, we monitored 156 nest-days of mockingbirds and 150 nest-days of baywings.

\section{Data analysis}

We defined a roost operationally as an area where a group of birds gather to spend the night. Because there were clear breaks in the distribution of birds (see Results), we used these breaks to delimit discrete roosts. We used home-range data previously published for the cowbirds tracked during the first two breeding seasons (Scardamaglia \& Reboreda 2014)

This article is protected by copyright. All rights reserved. 
to determine the distance between the individuals' resting locations and their diurnal locations (i.e. where they search for and locate host nests). To do this, we used the gCentroid function in rgeos package (Bivand \& Rundel 2016) in R 3.3.1 (R Core Team 2017) to calculate both the diurnal ranges centroids and roost centroids, and estimated the distance between these points for each individual.

\section{Site fidelity within a roost}

We defined fidelity to a roost as the percentage of nights on which a bird was searched for at a given roost that it was detected. For this estimate we used data from birds that were monitored on at least four nights (maximum available 23 nights).

\section{Fidelity within a roost}

To determine whether birds were faithful to the locations they used within a discrete roost, we compared the observed mean distance between night locations of each individual to the mean distance between locations of a simulated distribution of birds that settled within the roost at random each night. The simulation consisted of a Monte Carlo randomization procedure ( $n=1000$ runs) where bird locations along a linear roost could take integer values ranging from $0 \mathrm{~m}$ (the bird located in the same place in two different nights) to a maximum determined by the distance between opposite ends of the roost, with a $1 \mathrm{~m}$ resolution (see Online Supporting Material for more details of this simulation). We considered the observed distance to be significantly shorter than expected by chance if it fell below the $95^{\text {th }}$ percentile of the distribution generated by the simulation.

This article is protected by copyright. All rights reserved. 


\section{Association between Screaming Cowbird pairs}

To investigate whether pairs of Screaming Cowbirds maintain their diurnal association during the night, we used data from three females and three males that had been captured in pairs (i.e. individuals caught together in the same trap and showing high levels of association during the day, Scardamaglia \& Reboreda 2014). As a control, we recorded the frequency of association in the roost of two males and two females that were caught separately (i.e. in the same trap but at different times) and that did not show association during the day.

\section{Timing of roost departures and parasitism events}

We analysed the timing of both departure of females from the roost and parasitism events by generating a frequency distribution of the timing of both sets of events at five-minute intervals, and compared these between the two species using Mann-Whitney U-tests. The times of departures and parasitic events were standardized relative to sunrise on the day of recording for proper comparison, to account for variation in sunrise times through the season (http://www.usno.navy.mil/). Because it was not logistically possible to record departure times for all tagged females each morning, and record activity at all potential target nests, the data presented here are not direct observations of females departing from the roost and arriving at a host nest to parasitize on the same day.

This article is protected by copyright. All rights reserved. 


\section{RESULTS}

\section{Characteristics of roosting locations}

We recorded a total of 240 locations corresponding to 25 tagged Shiny Cowbird females (the other two tagged females were not detected in the area after tagging), 10 locations corresponding to five tagged Shiny Cowbird males (the other four tagged males were detected in the area during the morning but never around dusk, so they must have roosted outside our study area), 97 locations corresponding to 18 tagged Screaming Cowbird females (we did not record any roosting location for the other nine tagged females due to difficulty in accessing deep-forest locations), and 33 locations corresponding to the five tagged Screaming Cowbird males.

Radio-tracked Shiny Cowbird females and both sexes of Screaming Cowbird mainly used one roost, which was maintained throughout the breeding season (see below). Tagged Shiny Cowbird males were rarely found in roosts in the study area. We detected a 'main roost' for Shiny Cowbirds, where a few hundred birds roosted each night and where $93 \%$ of locations of tagged birds were recorded. The distance between the opposite ends of this roost was $755 \mathrm{~m}$ and it was located along a band of trees next to a low-use road, adjacent to the diurnal home-ranges of the tagged birds (Fig. 1a). Other smaller roosts (of only a few individuals) were recorded up to $4029 \mathrm{~m}$ apart. Screaming Cowbird roost locations were distributed in a band of forest (Fig. 1b). The distance between opposite ends of this roost was $1311 \mathrm{~m}$.

The median distance between the roost centroid and the diurnal range centroid was $494.9 \mathrm{~m}$ (range = 219-889 $\mathrm{m}, n=13$ ) for Shiny Cowbird females, $966.7 \mathrm{~m}$ (range = 628$1646 \mathrm{~m}, n=8)$ for Screaming Cowbird females and $974.5 \mathrm{~m}$ (range $=554-1710 \mathrm{~m}, n=5)$ for Screaming Cowbird males.

This article is protected by copyright. All rights reserved. 


\section{Fidelity to a roost}

Female Shiny Cowbirds were faithful to one roost throughout the breeding season. On average, females returned to the same roost $82 \% \pm 25 \%$ of the nights (mean \pm sd, range $=$ $17-100 \%, n=22$ females). The two females tracked during the seasons 2010/11 and 2013/14 used the same roost across years (Female 1: 100\% fidelity in both seasons; female 2: $100 \%$ fidelity in season 1 and $89 \%$ fidelity in season 2 ), while there was variability in the use of the roost for the female tracked across three breeding seasons ( $29 \%$ fidelity in season $1 ; 80 \%$ fidelity in season $2 ; 84 \%$ fidelity in season 3 ).

For Screaming Cowbirds, precise data were available only for the birds tagged with beeper radio-tags in seasons $2010 / 11$ and $2011 / 12$. Both males and females showed $100 \%$ fidelity to their roosting site ( $n=5$ females, $n=3$ males).

\section{Fidelity within a roost}

Shiny Cowbird females moved on average 62.3 $\pm 28.8 \mathrm{~m}$ (mean $\pm \mathrm{sd}$, range $=20-102 \mathrm{~m}, n=$ 15) between nights within a roost, Screaming Cowbird females moved $57.8 \pm 35.5 \mathrm{~m}$ (range $=16-122 \mathrm{~m}, n=11)$ and Screaming Cowbird males moved $44.6 \pm 18.9 \mathrm{~m}$ (range $=23-58 \mathrm{~m}$, $n=3$ ) (see Supporting Online Material Fig. S1). The distance between opposite ends in the distribution of birds, which defined the maximum values in our simulations, were $755 \mathrm{~m}$ and $1311 \mathrm{~m}$ for Shiny and Screaming Cowbirds respectively. Monte Carlo simulations showed that movements between nights were significantly shorter than expected by chance (i.e. if the birds located at random in the roost each night) for both Shiny (Fig. 2) and Screaming Cowbirds.

This article is protected by copyright. All rights reserved. 


\section{Association between Screaming Cowbird pairs}

Screaming Cowbird males and females that were trapped together and showed high levels of association during the day showed higher levels of association in the roost than control 'pairs'. The three pairs tracked were recorded associated in the roost in 12/12, 11/12 and 3/4 of the records respectively, while the two control 'pairs' did not show any association in any of the records $(0 / 4$ and $0 / 1$ respectively).

\section{Timing of roost departures and parasitism events}

Screaming Cowbird females left the roost earlier than Shiny Cowbird females (MannWhitney U-test, $U=41.5, P<0.001$, Shiny Cowbirds $n=19$, Screaming Cowbirds $n=11$, Online Supporting Material Table S1). Parasitic events occurred in a short time window in both species, earlier in Screaming than Shiny Cowbirds (Mann-Whitney U-test, $z=4.6, P<$ 0.001 , Shiny Cowbirds $n=21$, Screaming Cowbirds $n=11$, Online Supporting Material Table S1).

In Shiny Cowbirds, $86 \%$ of parasitic events occurred before sunrise, with $59 \%$ of roost departures coinciding with the parasitism time window (Fig. 3A). In Screaming Cowbirds $100 \%$ of parasitism events occurred well before sunrise, and $22 \%$ of roost departures occurred during the time window of parasitism (Fig. 3B).

\section{DISCUSSION}

We presented data on the dynamics of roost use by two species of brood parasitic cowbirds. Radio-tagging birds allowed us to analyse the individual temporal and spatial patterns of roost use. Females of both Shiny and Screaming Cowbirds mainly used a communal roost near their diurnal home-ranges throughout the breeding season. Males of Screaming, but

This article is protected by copyright. All rights reserved. 
not Shiny Cowbirds shared the females' communal roost, and pairs of Screaming Cowbirds maintained their association in the roost at night. Females of both species left the roost before and after sunrise, with a fraction of departures coinciding with the time window of parasitism. Screaming Cowbird females departed from the roost and parasitized nests earlier than Shiny Cowbird females.

Most radio-tagged cowbirds were found roosting in large groups. Similar to other communally roosting species (reviewed by Beauchamp 1999), the benefits of roosting communally for cowbirds may include a lower predation probability (through dilution of risk, increased anti-predator vigilance or predator confusion) and higher probability of finding a mate (Bijleveld et al. 2010). Furthermore, Ward and Zahavi (1973) proposed that bird assemblages such as roosts could work as information centres, where individuals that do not have information on the location of good feeding sites can obtain such knowledge from individuals that do. In cowbirds, the possibility that females may eavesdrop, acquiring information not on feeding sites but on the location of suitable target nests, seems a likely additional benefit to roosting communally. Indirect evidence for active following has been recorded in the Shiny Cowbird, where females frequently arrive at host nests in tandems, probably due to uninformed females 'tailing' those that fly determinedly towards a previously prospected target (Gloag et al. 2013). As with the foraging version of the Ward-Zahavi hypothesis, this scenario does not identify benefits for the informed animals, but only for those that follow. In fact, since cowbird females typically destroy eggs before laying, being followed must be a significant liability. Identifying whether information transfer about potential host nests occurs, and how the balance of costs and benefits combine to determine roosting behaviour, remains a challenge for further research.

Shiny Cowbird females and Screaming Cowbirds of both sexes used roosts within close range of their diurnal home-ranges, namely the areas where they search for host nests (Scardamaglia \& Reboreda 2014), and showed high levels of fidelity both between and within roosts. These findings may be related to the fact that these brood parasites must

This article is protected by copyright. All rights reserved. 
leave their roosting place and navigate towards host nests within a limited time window and in conditions of very low light intensity. Navigating from a well-known area may therefore be more important than reducing the distance between roosting-site and target nest. The fact that we did not find male Shiny Cowbirds roosting in the area near their diurnal home-ranges is consistent with this idea because they do not search for or relocate host nests and consequently do not need to navigate in the dark. It is possible that Shiny Cowbird males roost near areas of higher food availability and move during the morning to areas where females search for host nests to mate. In a previous study, Scardamaglia and Reboreda (2014) showed that Shiny and Screaming Cowbird females maintain relatively stable diurnal ranges on consecutive days, which would allow females to monitor host nests' progress and in this way, be able to synchronize their laying with that of the host. This study also provides some evidence that cowbird females fly directly from the roost to target host nests at dawn, with females having little chance of locating suitable target nests on laying days, other than by following informed females. In a related study, Scardamaglia et al. (2017) showed that Shiny and Screaming Cowbird females conducted prospecting visits to host nests the days before parasitism. Moreover, in this study we show that cowbird females are faithful to their nocturnal roosting sites in addition to the constant diurnal home-ranges and prospecting areas shown in previous studies (Scardamaglia \& Reboreda 2014, Scardamaglia et al. 2017).

The strong roosting association found for pairs of Screaming Cowbirds shows that diurnal social monogamy (Scardamaglia and Reboreda 2014) extends to the roost as well. While it has been proposed that male and female Screaming Cowbirds search for and relocate nests together (Friedmann 1929, Mason 1987), since they travel in pairs throughout the day, it remains unclear whether males actively participate in these tasks or if their presence alongside females near host nests is simply the result of mate guarding. The relative enlargement of the hippocampus (an area of the brain involved in encoding spatial information, O'Keefe \& Nadel 1978) in both sexes in this species, as opposed to the sex

This article is protected by copyright. All rights reserved. 
differences found between males and females in Shiny Cowbirds (Reboreda et al. 1996), where females search for and later relocate host nests alone, is consistent with the idea that male and female Screaming Cowbirds share the nest-searching and relocating tasks. Sharing the roost would be adaptive for Screaming Cowbird pairs if males just guard females or assist them in nest searching and relocation. This socially monogamous mating strategy is unusual among brood parasites (Hauber \& Dearborn 2003). Several hypotheses regarding avian mating systems predict that the absence of parental care should lead to an increase in numbers of mates for both females and males (Hauber \& Dearborn 2003), as illustrated by the social promiscuity of Shiny Cowbirds (Mason 1987, Scardamaglia \& Reboreda 2014), also confirmed by our observations on roosting. While the genetic mating systems still need corroboration, and more information is necessary about the daily routines and copulatory behaviour of both species, it is reasonable to expect that the marked difference in mating systems responds to differences in parasitic specialization, an aspect of mating that to our knowledge has not been explored in any detail to date.

Parasitic cowbird females, as opposed to nest-building species, are constrained to leave their roosting place and reach target nests within a limited time window, between completion of egg formation and daylight. However, on days when they do not have an egg to lay, and the morning will be spent only on feeding and searching for nests, they can leave the roost later. Our data support this expectation. We found that $59 \%$ of Shiny Cowbird and $22 \%$ of Screaming Cowbird roost departures overlapped with the parasitism time window. Thus, although we cannot rule out that some roost departures that occurred during the laying time window may have not been associated with egg-laying, most departures occurring afterwards must have been non-parasitic visits or females leaving the roost to forage. The timing of departure from the roost may be a predictor of whether a female is on a laying day or not, and consequently help to estimate the number of eggs laid by female cowbirds during the breeding season. The difference observed between species in the percentage of roost departures that overlap in timing with the distribution of parasitism

This article is protected by copyright. All rights reserved. 
events may be due to an underestimate of early departures by Screaming Cowbirds. Data for departures from earlier than 50 min before sunrise are missing (there are parasitic events recorded in the -55 to -50 min time bin but no roost departures recorded for the same period or earlier). This may be attributed to the different methods that were used to record each type of event: parasitism events were recorded by automatic data-loggers in the nests that worked $24 \mathrm{~h}$ a day, while departures from the roost were recorded by a researcher with a hand-held tracking receiver in the roost area. Hence, there was a limit on the recording of times and access to roost locations, especially for Screaming Cowbirds. This leads to a potential underestimate of the percentage of departures from the roost that coincide with the parasitism time window in Screaming Cowbirds.

To summarize, we showed that throughout the breeding season females of Shiny and Screaming Cowbirds roosted near the area at which they searched for and parasitized host nests and that the timing of roost departures can potentially predict parasitic behaviour. Our study illustrates how the use of radio-tracking technologies may help to understand relatively poorly known aspects of the behaviour of brood parasites.

We thank Fundación Elsa Shaw de Pearson for allowing us to conduct the study in Reserve El Destino and Daniel Campioni for help in preparation of Figure 1.

Funding statement: R.C.S was supported by a scholarship from the Consejo Nacional de Investigaciones Científicas y Técnicas (CONICET). J.C.R is a Research Fellow of CONICET. This work was supported by grants from Agencia Nacional de Promoción Científica y Tecnológica and University of Buenos Aires. None of our funders had any influence on the content of the submitted or published manuscript. None of our funders require approval of the final manuscript to be published.

Ethics statement: All work complied with Argentinean Law.

This article is protected by copyright. All rights reserved. 
Authors contribution: R.C.S., A.K. and J.C.R. conceived the idea, design and formulated hypothesis, R.C.S. collected the data, R.C.S, A.K. and J.C.R. wrote the paper, R.C.S. analysed the data.

\section{LITERATURE CITED}

Adams, T. L. (2011). Roost site seleciton of Dunlin (Calidris alpina) on Arcata Bay, Humboldt Bay, Humboldt County, California. M.S. Thesis. The Faculty of Humboldt State University.

Beauchamp, G. (1999). The evolution of communal roosting in birds : origin and secondary losses. Behav. Ecol. 10:675-687. doi: 10.1093/beheco/10.6.675

Béchet, A., J.-F. Giroux, G. Gauthier, and M. Bélisle (2010). Why roost at the same place? Exploring short-term fidelity in staging snow geese. Condor 112:294-303. doi: $10.1525 /$ cond.2010.090050

Bijleveld, A. I., M. Egas, J. A. van Gils, and T. Piersma (2010). Beyond the information centre hypothesis: Communal roosting for information on food, predators, travel companions and mates? Oikos 119:277-285. doi: 10.1111/j.1600-0706.2009.17892.x

Bivand, R., and C. Rundel (2016). rgeos: Interface to Geometry Engine - Open Source (GEOS). R package version 0.3-20. [Online.] Available at https://cran.rproject.org/package=rgeos.

Conklin, J. R. J., M. a Colwell, and D. B. Lank (2007). Diurnal and nocturnal roost site fidelity of Dunlin (Calidris alpina pacifica) at Humboldt Bay, California. Auk 124:677-689. doi: 10.1642/0004-8038(2007)124[677:DANRSF]2.0.CO;2

Cruz, A., T. Manolis, and R. Andrews (1990). Reproductive interactions of the Shiny Cowbird Molothrus bonariensis and the Yellow-hooded Blackbird Agelaius icterocephalus in

This article is protected by copyright. All rights reserved. 
Trinidad. Ibis 132:436-444.

De Mársico, M. C., B. Mahler, M. Chomnalez, A. Di Giácomo, and J. C. Reboreda (2010). Host Use by Generalist and Specialist Brood-Parasitic Cowbirds at Population and Individual Levels. Adv. Study Behav. 42:83-121. doi: 10.1016/S0065-3454(10)42003-3

Dhondt, A. A., M. J. L. Driscoll, and E. C. H. Swarthout (2006). House Finch Carpodacus mexicanus roosting behaviour during the non-breeding season and possible effects of Mycoplasmal conjunctivitis. Ibis 149:1-9. doi: 10.1111/j.1474-919X.2006.00588.x

du Plessis, M. a., W. W. Weathers, and W. D. Koenig (1994). Energetic benefits of communal roosting by Acorn Woodpeckers during the nonbreeding season. Condor 96:631-637. doi: 10.2307/1369466

Feare, C., and M. Zaccagnini (1993). Roost departure by Shiny Cowbirds (Molothrus bonariensis). Hornero 13:292-293.

Fiorini, V. D., and J. C. Reboreda (2006). Cues used by shiny cowbirds (Molothrus bonariensis) to locate and parasitise chalk-browed mockingbird (Mimus saturninus) nests. Behav. Ecol. Sociobiol. 60:379-385. doi: 10.1007/s00265-006-0175-3

Fraga, R. M. (1985). Host-parasite interactions between Chalk-browed Mockingbirds and Shiny Cowbirds. Orn. Monogr. 36:829-844.

Fraga, R. M. (1991). The social system of a communal breeder, the bay-winged cowbird Molothrus badius. Ethology 89:195-210. doi:10.1111/j.14390310.1991.tb00304.x

Fraga, R. M. (1998). Interactions of the parasitic Screaming and Shiny Cowbirds (Molothrus rufoaxillaris and $M$. bonariensis) with a shared host, the Bay-winged Cowbird ( $M$. badius). In Parasitic birds and their hosts. Studies in coevolution (S. I. Rothstein and S. K. Robinson, Editors). Oxford University Press, New York, NY, pp. 173-193.

This article is protected by copyright. All rights reserved. 
Friedmann, H. (1929). The Cowbirds. A Study in the Biology of Social Parasitism (C. Thomas, Editor). Springfield, Illinois, pp. 57-144.

Gates, J. E., and D. R. Evans (1998). Cowbirds breeding in the Central Appalachians: spatial and temporal patterns and habitat selection. Ecol. Appl. 8:27-40.

Gloag R., V. D. Fiorini, J. C. Reboreda, and A. Kacelnik (2012) Brood parasite eggs enhance egg survivorship in a multiply parasitized host. Proc. R. Soc. B 279:1831-9. doi: 10.1098/rspb.2011.2047

Gloag, R., V. D. Fiorini, J. C. Reboreda, and A. Kacelnik (2013). The wages of violence: mobbing by mockingbirds as a frontline defence against brood-parasitic cowbirds. Anim. Behav. 86:1023-1029. doi: 10.1016/j.anbehav.2013.09.007

Hahn, D., J. Sedgwick, I. Painter, and N. Casna (1999). A spatial and genetic analysis of cowbird host selection. Stud. Avian Biol. 18:204-217.

Hauber, M. E., and D. C. Dearborn (2003). Parentage without parental care: what to look for in genetic studies of obligate brood-parasitic mating systems. Auk 120:1-13.

Hoy, G., and J. Ottow (1964). Biological and oological studies of the molothrine cowbirds (Icteridae) of Argentina. Auk 81:186-203.

Kattan, G. H., A. Posada, D. F. Arenas, J. L. Moreno, and Á. Barrera (2016). Flocking behavior of Shiny Cowbirds (Molothrus bonariensis) at feeding areas during the daily cycle. Wilson J. Ornithol. 128:441-445. doi: 10.1676/1559-4491-128.2.441

Laughlin, A. J., D. R. Sheldon, D. W. Winkler, and C. M. Taylor (2014). Behavioral drivers of communal roosting in a songbird: a combined theoretical and empirical approach. Behav. Ecol. 25:734-743. doi: 10.1093/beheco/aru044

Mason, P. (1980). Ecological and evolutionary aspects of host selection in cowbirds. D. Biol. Thesis, University of Texas, Austin.

This article is protected by copyright. All rights reserved. 
Mason, P. (1987). Pair formation in cowbirds: evidence found for Screaming but not Shiny Cowbirds. Condor 89:349-356.

Morrison, D. W., and D. F. Caccamise (1985). Ephemeral roosts and stable patches - A radiotelemetry study of communally roosting starlings. Auk 102:793-804.

Morrison, D. W., and D. F. Caccamise (1990). Comparison of roost use by three species of communal roostmates. Condor 92:405-412.

O’Keefe, J., and L. Nadel (1978). The Hippocampus As A Cognitive Map. Oxford University Press, Oxford.

Paquet, M., C. Doutrelant, M. Loubon, F. Theron, M. Rat, and R. Covas (2016). Communal roosting, thermoregulatory benefits and breeding group size predictability in cooperatively breeding sociable weavers. J. Avian Biol. 47:749-755. doi: 10.1111/jav.00916

Rappole, J. H., and A. R. Tipton (1991). New harness design for attachment of radio transmitters to small passerines. J. Field Ornith. 62:335-337.

R Core Team (2017). R: A language and environment for statistical computing. R Foundation for Statistical Computing. [Online.] Available at https://www.r-project.org/.

Reboreda, J. C., N. Clayton, and A. Kacelnik (1996). Species and sex differences in hippocampus size in parasitic and non-parasitic cowbirds. Neuroreport 7:505-508.

Scardamaglia, R. C., and J. C. Reboreda (2014). Ranging behavior of female and male Shiny Cowbirds and Screaming Cowbirds while searching for host nests. Auk 131:610618. doi: 10.1642/AUK-14-54.1

Scardamaglia, R. C., V. D. Fiorini, A. Kacelnik, and J. C. Reboreda (2017). Planning host exploitation through prospecting visits by parasitic cowbirds. Behav. Ecol. Sociobiol. 71:23. doi: 10.1007/s00265-016-2250-8

This article is protected by copyright. All rights reserved. 
Thompson, F. (1994). Temporal and spatial patterns of breeding Brown-headed Cowbirds in the midwestern United States. Auk 111:979-990.

Tuero, D. T., V. D. Fiorini, and J. C. Reboreda (2007). Effects of shiny cowbird parasitism on different components of house wren reproductive success. Ibis 149, 521-527.

Ursino, C. A., M. C. De Mársico, M. Sued, A. Farall, and J. C. Reboreda (2011). Brood parasitism disproportionately increases nest provisioning and helper recruitment in a cooperatively breeding bird. Behav. Ecol. Sociobiol. 65:2279-2286. doi: $10.1007 / \mathrm{s} 00265-011-1238-7$

Ward, P., and A. Zahavi (1973). The importance of certain assemblages of birds as "information-centres" for food-finding. Ibis 115:517-534. doi: 10.1111/j.1474919X.1973.tb01990.x

Weatherhead, P. J. (1987). Field tests of information transfer in communally roosting birds. Anim. Behav. 35(2):614-615.

White, G. C., and R. A. Garrott (1990). Chapter 4: Estimating Animal Locations. In: Analysis of Wildlife Radio-Tracking Data. Academic Press, San Diego, California.

Winkler, D. W. (2006). Roosts and migrations of swallows. Hornero 21:85-97.

Yom-Tov, Y. (1979). The disadvantage of low positions in colonial roosts: an experiment to test the effect of droppings on plumage quality. Ibis 121:331-333.

Figure 1. Study area with area used during the day (polygon), roosting locations centroids and locations of data-loggers (i.e. monitored host nests) with marked parasitism events for (a) Shiny Cowbirds and (b) Screaming Cowbirds.

This article is protected by copyright. All rights reserved. 
Figure 2. Observed mean distance between the location of each female within the roost for a sample of 15 female Shiny Cowbirds and frequency distribution of expected observations of mean distances if females settled within the roost at random each night. The observed distance between nights falls below the $95^{\text {th }}$ percentile of the distribution, indicating that females located significantly closer to the locations they used previously than expected by chance.

Figure 3. Distribution of the proportion of roost departures and parasitic events that occurred at different time intervals for Shiny Cowbird (A) and Screaming Cowbird (B) females. Shiny Cowbird roost departure times $(n=97)$ correspond to 19 Shiny Cowbird females in 1-14 different days. Shiny Cowbird parasitism events $(n=21)$ were recorded either by videorecordings or the automated telemetry system at Chalked-browed Mockingbird nests and correspond to a maximum of 18 different females (some females could not be reliably identified in video-recordings) in 20 different nests. Screaming Cowbird roost departure times $(n=28)$ correspond to 11 Screaming Cowbird females in 1-6 different days. Parasitism events $(n=11)$ were recorded by the automated telemetry system at Baywing nests and correspond to 7 different females in 7 different nests.

This article is protected by copyright. All rights reserved. 
(A) Shiny Cowbirds
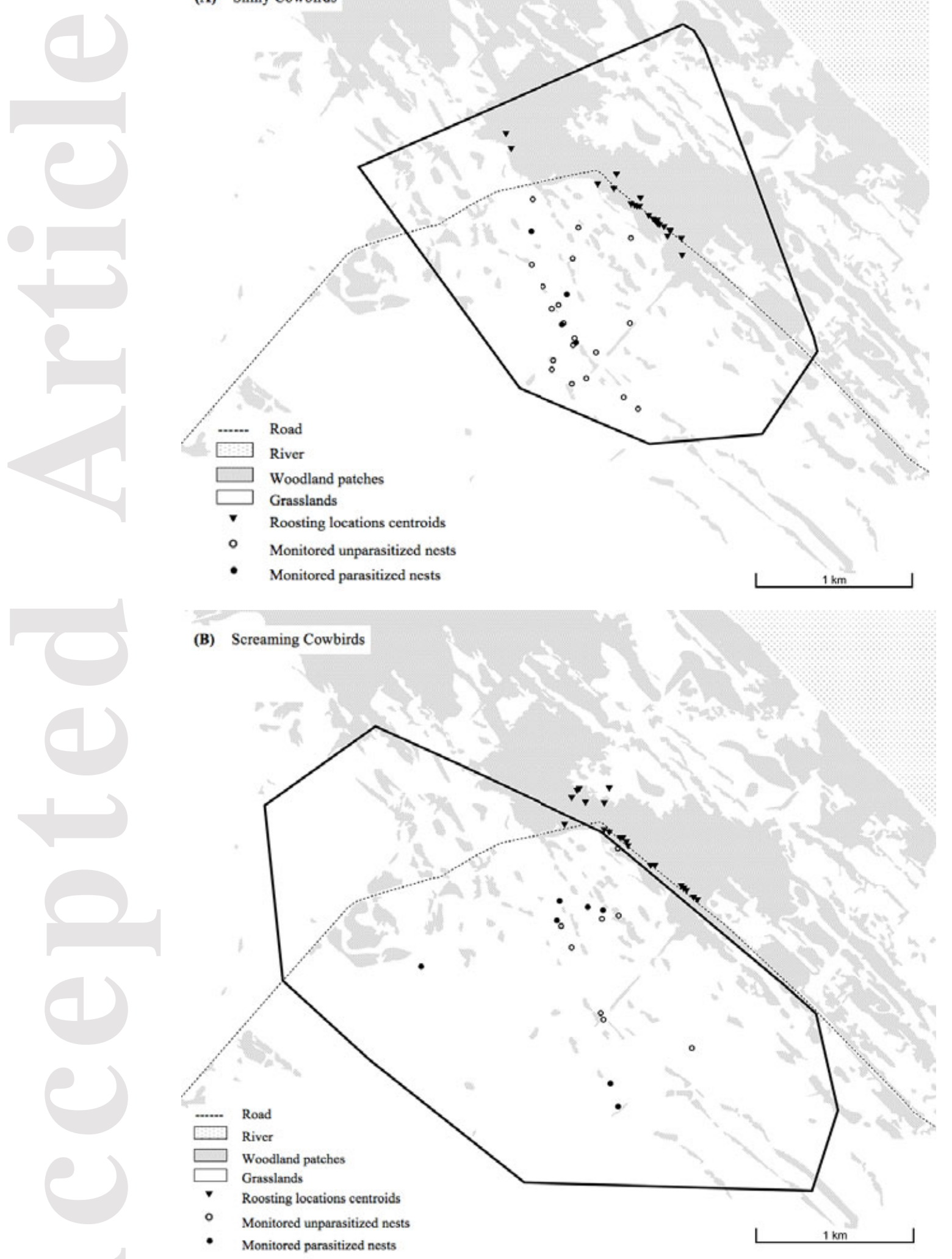

Figure 1 


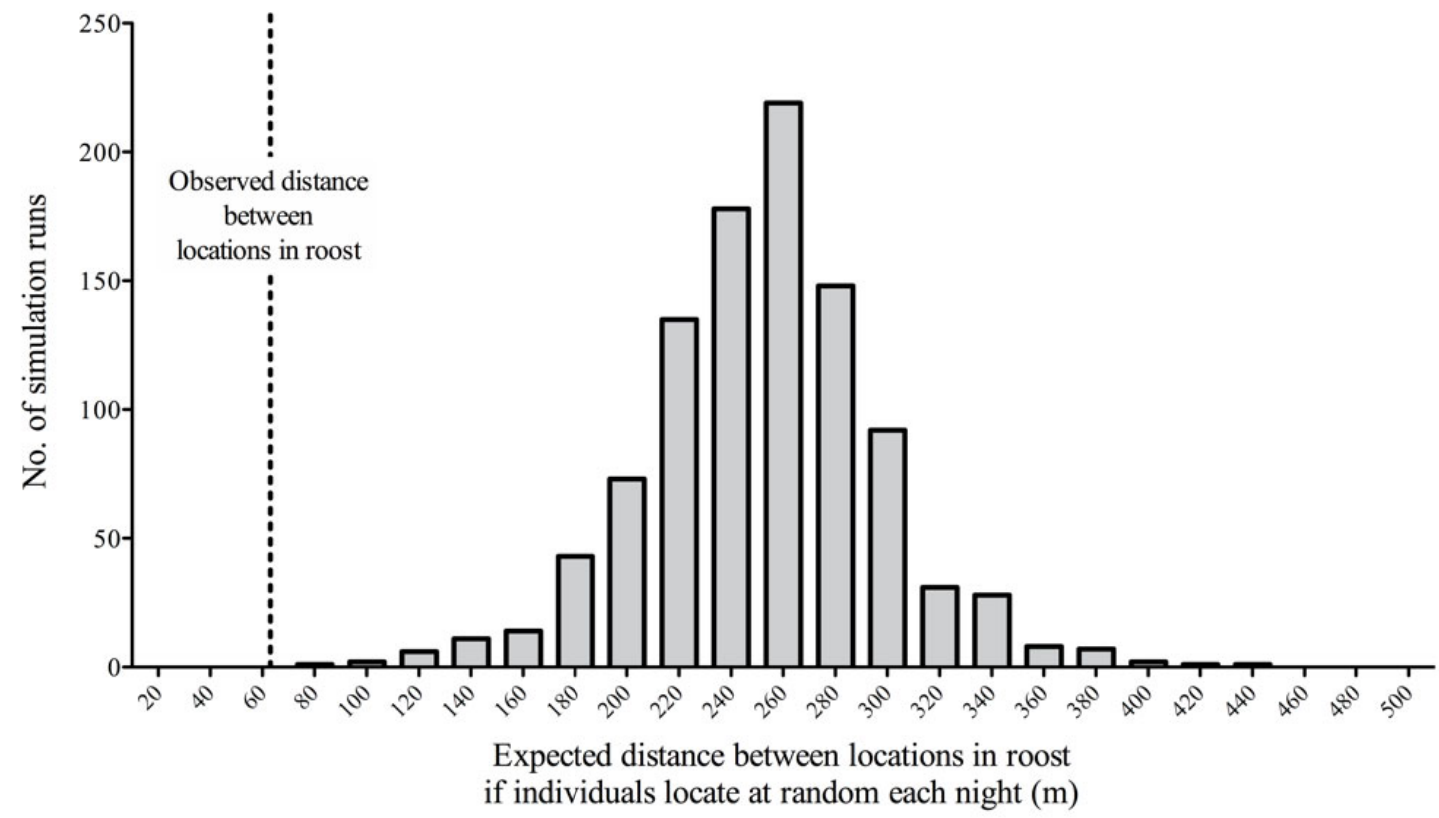

Figure 2 


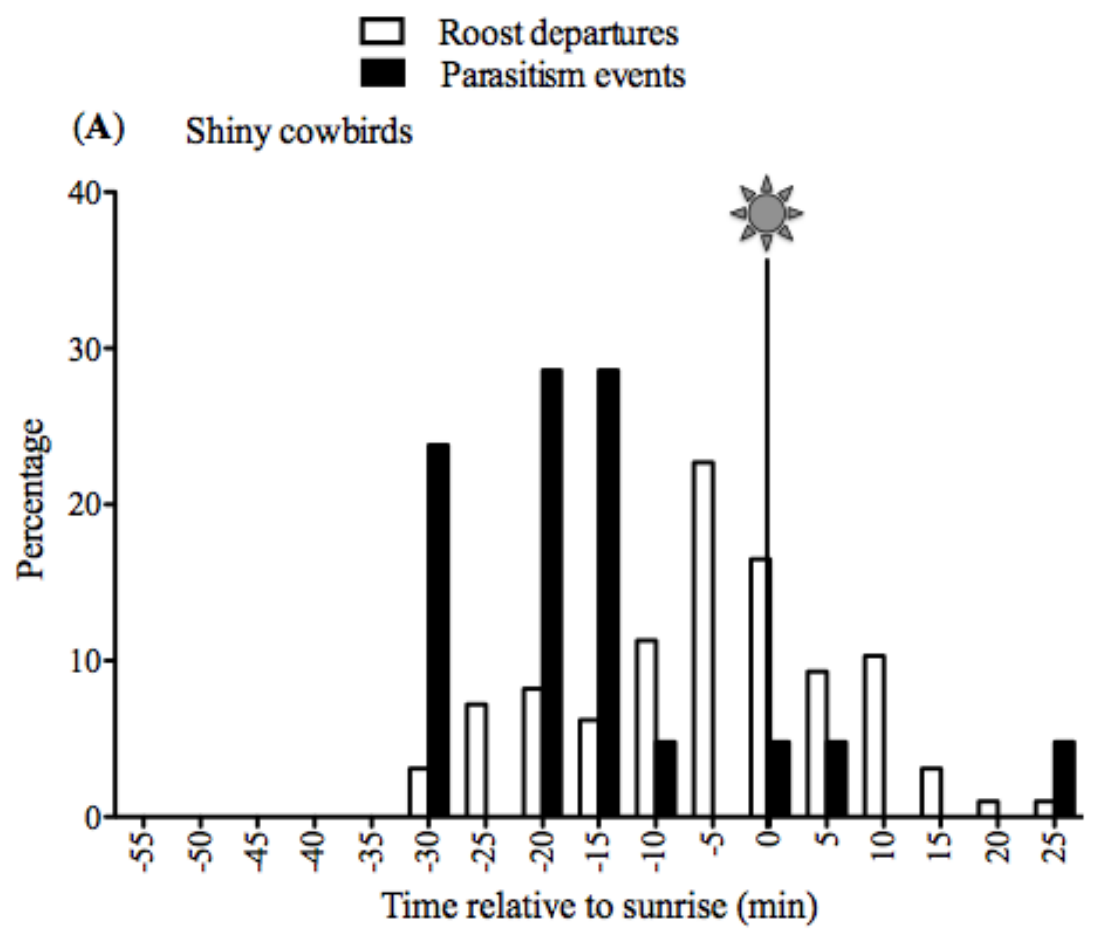

(B) Screaming cowbirds

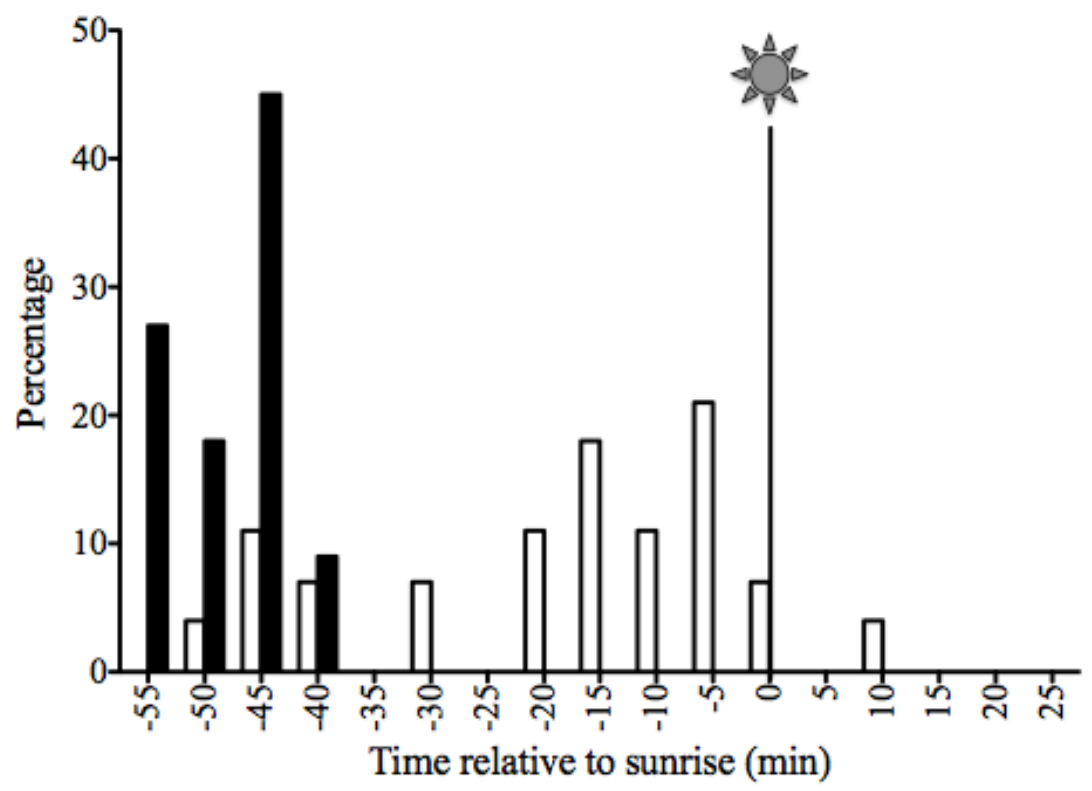

Figure 3 